\title{
Manuais de didática da história: contribuições para entender suas especificidades. ${ }^{1}$
}

\author{
Didactic manuals of history: understanding their specificities.
}

\author{
Osvaldo Rodrigues Junior ${ }^{2}$ \\ Tânia Maria Figueiredo Braga Garcia
}

RESUMO

Apresenta resultados de investigação sobre a natureza dos manuais de Didática da História produzidos no Brasil entre 1997 e 2013. Explicita características da estrutura e forma de sete obras que correspondem à definição de manuais didáticos entendidos como aqueles que têm a finalidade de orientar professores em suas práticas de ensino ou "ensinam a ensinar". Parte do pressuposto de que a existência destes manuais configura a composição do código disciplinar da História e da Didática da História enquanto disciplina responsável por orientar o ensino da História. Compreende ainda que a Didática da História é a "ciência do aprendizado histórico" e que, como tal, pode ser dirigida a três tarefas: a tarefa empírica; a tarefa reflexiva; e a tarefa normativa. Os resultados indicam que por sua natureza os manuais de Didática da História se distingue de outros textos escolares da disciplina. Essa distinção pode ser observada na estrutura didática que define as obras como manuais de Didática da História.

Palavras-chave: Manuais de Didática da História. Didática da História. Textos Escolares. Formação de professores de História. no de História.

1 A pesquisa teve apoio parcial do CNPq, com recursos de Bolsa Produtividade.

2 Doutor em Educação pela Universidade Federal do Paraná - UFPR. Professor Adjunto do Departamento de História da Universidade Federal de Mato Grosso - UFMT.

3 Doutora em Educação pela Universidade de São Paulo - USP. Professora do Programa de Pós-Graduação em Educação da Universidade Federal do Paraná - UFPR. Bolsista Produtividade em Pesquisa do CNPq. 


\section{ABSTRACT}

This paper presents the results of the researchwhich analyzed didactic manuals of History produced in Brazil, between 1997 and 2013. It describes the structure of seven books that are defined as didactic manuals or guides for history teachers practices. The existence of these manuals sets the framework of the disciplinary code of history and of history didactics. In the analysis, we accept the assumption that history didactics is the "science of historic learning" and it can be directed to three tasks: the empirical task; the reflective task; and the normative task. The results indicate that the authors intend to have a dial ogue with teachers of teacher education courses, with teachers who are studying to be teachers, and with teachers who work in schools and need support to organize their classes. The didactic manuals are structured to give this support.

Keyword: Teaching of history textbooks. Didactics of History. History teachers training. History teaching.

\section{Manuais Para Professores: Um Conjunto Diverso e Complexo}

Em texto dedicado ao estado da arte da história dos livros e das edições didáticas, Alain Choppin (2004) identifica a existência de dois problemas nas pesquisas desse campo. $O$ primeiro relaciona-se a não existência de obras síntese, podendo-se caracterizar as publicações como fragmentadas já que ocorrem principalmente na forma de artigos, dispersos em periódicos de diferentes campos do conhecimento.

O segundo problema apontado pelo autor diz respeito ao léxico dos investigadores, e essa questão constitui-se em fio condutor das considerações apresentadas neste artigo. Muitas vezes os estudiosos do tema não definem os seus objetos de pequisa, usando o termo genérico "livros didáticos" sem proceder a um trabalho de precisão do conceito que, assim, acaba por referir-se a um conjunto extremamente diversificado de edições didáticas.

De forma semelhante, o termo manuais didáticos é utilizado nas pesquisas para identificar diferentes tipos de obras, evidenciando o problema léxico citado e as dificuldades que as classificações têm para apreender a diversidade de obras existentes. Batista (2000, p. 548) afirma que:

a categoria dos manuais didáticos, por exemplo, agrupa um conjunto bastante heterogêneo de textos, que se propõem a assumir diferentes funções no trabalho cotidiano de sala de aula. Um dos fatores responsáveis por essa diversidade está relacionado com as disciplinas e com os graus e níveis de ensino a que os textos e impressos se destinam 
e com os diferentes modos por meio dos quais as diversas disciplinas se consolidaram historicamente.

Na tentativa de condensar conceituações propostas em diferentes trabalhos sobre o tema, o autor apresenta a ideia de que "seria, afinal, aquele livro ou impresso empregado pela escola, para desenvolvimento de um processo de ensino ou formação" (BATISTA, 2000, p. 534). Mas as dificuldades e limites dessa conceituação são sugeridos por ele mesmo, em decorrência de alguns fatores, entre os quais:

a) a heterogeneidade de suportes de textos didáticos que circulam na escola;

b) a variação dos processos de reprodução dos impressos que incluíram e incluem a escrita manual, o antigo mimeógrafo, as fotocopiadoras e os meios digitais;

c) a variação no processo de produção, que inclui as possibilidades de que os impressos sejam "gerados para a escola, destinados à escola ou utilizados pela escola" (BARISTA, 2000, p. 545);

d) as diferentes formas pelas quais os impressos estabelecem formas diferenciadas de estruturação, organização e, portanto, de utilização, articulando-se com o trabalho pedagógico e exercendo funções, buscando leitores, construindo relações.

Para o autor, apesar das dificuldades de conceituar o livro didático que decorrem de todas essas dimensões envolvidas, é necessário que o pesquisador estrabeleça parâmetros para sua pesquisa. Dessa forma, "a apreensão de um livro didático e sua conceituação devem ser o resultado de um conjunto de decisões controladas, tendo em vista aquelas dimensões do livro que se revelaram [...] problemáticas" (BATISTA, 2000, p. 567).

Neste sentido, deve-se destacar nestas notas introdutórias que as obras que constituem o centro de atenção na pequisa realizada são livros impressos, produzidos por editoras comerciais e que tem por objetivo orientar o ensino. Do ponto de vista dos leitores a que se destinam, são livros pensados para professores - sejam aqueles que estão em processos de formação inicial, sejam aqueles que já atuam como profissionais. Nesse sentido, constituemse em um grupo particular de obras didáticas.

Nagle (2009, p.22), ao tratar da literatura pedagógica no contexto da Primeira República, aponta a existência de uma diversidade de manuais que foram escritos para os mestres e destaca, dentre as publicações, obras de "caráter essencialmente didático, para não dizer exclusivamente metodológico". 
Apesar da grande circulação dessas obras ao longo século xx e de sua permanência no século XXI, a pesquisa sobre os manuais para os professores pode ser considerada, ainda, incipiente quando comparada à temática dos livros didáticos destinados aos alunos. Essa constatação foi feita Guerreña, Ossenbach e Pozzo (2005) no contexto iberoamericano, embora já se possam registrar trabalhos que permitiram avanços na compreensão desse tipo de literatura que circula no âmbito educacional.

Esses estudos vêm lançando luzes tanto sobre esses objetos como sobre suas relações com outros elementos da cultura escolar, como concepções e métodos de ensino, conceitos de aprendizagem, constituição da profissionalidade docente, entre outros. No caso brasileiro, alguns trabalhos vêm sendo produzidos desde a década de 1990 e privilegiam as diferentes áreas do conhecimento, com maior incidência nos campos da História da Educação, Didática Geral e da Pedagogia.

Marta Maria Chagas de Carvalho e Maria Rita de Almeida Toledo (2007, p. 1) em estudo sobre a Biblioteca de Educação organizada por Lourenço Filho, e a coleção Atualidades Pedagógicas, organizada por Fernando de Azevedo, afirmam que "uma coleção de livros é sempre produto de uma estratégia editorial dotada de características que lhe são específicas". Para elas, a publicação dessas coleções tem como objetivos: 1) ampliar o mercado editorial; 2) adequar o livro a um objetivo cultural específico, logo a um público específico.

As autoras localizam o boom das edições didáticas no Brasil na década de 1930, momento em que surgem as coleções pedagógicas analisadas, identificando que as obras da Biblioteca de Educação "[...] se dispõem como peças de um conjunto harmônico destinado a constituir a cultura pedagógica do professorado" (CARVALHO; TOLEDO, 2007, p. 7). Tal entendimento permite corroborar a existência de manuais destinados aos profesores enquanto um tipo específico de literatura pedagógica.

Outro destaque se faz, aqui, ao trabalho de Diana Vidal (2001). Tendo como problemática o estudo da formação docente no Instituto de Educação do Distrito Federal entre 1932 e 1937, utilizou como procedimentos de investigação entrevistas, leis, decretos, regulamentos, programas, plantas arquitetônicas, correspondências, fotografias, livros, revistas, artigos etc. A autora identifica a apropriação dos discursos, a partir da análise das materialidades do projeto de formação docente dos escolanovistas localizando entre os elementos dessa materialidade os livros ou manuais escolares. Dessa forma, identifica a importância da literatura pedagógica destinada ao professor como constituidora da materialidade dos discursos sobre a formação de professores.

Outros trabalhos poderiam ser relembrados, contudo, a intenção aqui é contribuir com alguns elementos para a reconceitualização de tais obras. Dessa forma, deve-se apontar as 
contribuições dadas por Vivian Batista da Silva (2003) que, ao analisar os manuais destinados a normalistas, define os "manuais pedagógicos" como obras destinadas:

[...] ao ensino de disciplinas profissionalizantes dos currículos de instituições de formação docente, no caso, aquelas diretamente relacionadas com questões educacionais, a saber, a pedagogia, a didática, a metodologia e a prática de ensino (SILVA, 2003, p. 30).

Na tese intitulada Saberes em viagem nos manuais pedagógicos: construções da escola em Portugal e no Brasil (1870-1970), Vivian Batista da Silva (2005) aprofunda a análise dos manuais indicando que eles compõem o que identifica como uma "gramática do ensino".

Ainda de acordo com a autora, os manuais analisados apresentam "prescrições minuciosas sobre como agir em sala de aula" e são marcados pelo hibridismo cultural ou a troca entre os intelectuais da educação. Para explicar esse processo, a autora utiliza a metáfora da viagem comparando os escritores dos manuais aos viajantes, transportadores de saberes e ideias.

Em relação aos resultados, os manuais publicados em meados do século XX apresentaram uma perspectiva do "saber fazer", "uma dimensão técnica do ofício docente" (SILVA, 2005, p. 71); dessa forma "na maior parte das vezes restringiram o seu conteúdo a uma espécie de receituário de como exercer o magistério" (SILVA, 2005, p. 294). A autora afirma também que:

os manuais pedagógicos participaram da fundação de determinados discursos, traduzindo-os e dando-os a ler. Essa foi uma das instâncias de produção dos autores da área educacional: a articulação de suas ideias foi a articulação das ideias que sustentaram as proposições para as atividades de alunos e professores na escola e essas leituras foram sendo construídas desde finais do século XIX.

Assim, Silva (2003, 2005) contribuiu para a discussão na direção de identificar elementos que permitem definir os "manuais pedagógicos" como aqueles livros destinados aos profesores, que se preocupam com os saberes "profissionalizantes" ou com os saberes responsáveis pela formação docente. 
Portanto, a ideia de obras e de coleções específicas para professores atravessou o século $\mathrm{XX}$ e chegou aos dias de hoje. Esse tipo de publicação parece ter um mercado relativamente permanente, como apontado por Hegeto e Garcia (2012) no caso específico de manuais de Didática Geral. Segundo as autoras, há obras reeditadas desde 1984, basicamente com a mesma estrutura de conteúdos, e que é referida em bibliografia de cursos e de concursos para docentes.

Do conjunto de manuais pedagógicos, interessa destacar aqui exatamente aqueles que se propõem a orientar as atividades de ensino. Além dos manuais de metodologia e de didática geral, podem ser identificados manuais de metodologia e didática especial, responsáveis por propor métodos e atividades de ensino nas disciplinas específicas. Essas obras destinadas ao professor ganharam impulso nos anos 1950 e 1960.

Sobre a definição de manuais de Didática, Bufrem, Garcia e Schmidt (2006, p. 123) indicam que estes textos, por serem manuais, "apresentam a proposta de, a um só tempo introduzir um tema e sumariá-lo". Mas se diferenciam dos manuais destinados aos alunos e também são distintos de outros também destinados aos professores, uma vez que:

[...] propõem métodos e atividades de ensino de determinadas disciplinas indica, também, a necessidade de explicitação do que se entende pelo conjunto de conhecimentos veiculados por estes manuais, ou seja, que tipo de saberes são constitutivos destas publicações destinadas aos professores. (BUFREM; GARCIA; SCHMIDT, 2006, p. 123).

Segundo as autoras, outra especificidade desses manuais destinados a orientar professores reside no fato de não apresentarem os conteúdos específicos de uma disciplina escolar, como História Antiga ou História da América, no caso da História, caracterizando-se por apresentarem "uma gama de saberes que podem ser incluídos nos saberes e práticas próprios da Didática das disciplinas" (BUFREM; GARCIA; SCHMIDT, 2006, p. 123).

Assim, os manuais de Didática Específica ou Didática Especial são compreendidos como um objeto diferenciado em relação aos livros didáticos destinados aos alunos e, também, diferenciado de outro tipo de obras destinadas aos professores, que discutem questões relacionadas à educação e ao ensino, mas sem apresentar uma proposta de organização didática que possa orientar os professores em suas práticas.

As autoras identificaram os manuais de Didática Específica ou Didática Especial como manuais que ensinam a ensinar. O papel destes manuais é, portanto, de "exercerem a função 
de mediação entre o conhecimento científico específico e os modos de ensiná-lo na sala de aula" (BUFREM; SCHMIDT; GARCIA, 2006. p. 4).

Entre os trabalhos que tomam esses manuais como objetos, destacam-se aqui os de Garcia $(2007,2010)$ que abordam elementos relacionados aos manuias de Didática Geral. No caso específico da História, trabalhos como os de Schmidt (2004, 2005, 2008, 2012) e Urban (2009) identificaram, a partir dos manuais destinados a professores, a existência de um "código disciplinar da História e da Didática da História".

Com apoio em Cuesta Fernandez (1997), as autoras compreendem essas obras como "textos visíveis" que permitem evidenciar elementos dos códigos disciplinares. Como resultados dessas investigações, por exemplo, aponta-se a contribuição de Schmidt (2012). A partir da análise dos manuais de Didática da História, a autora construiu uma proposta de periodização do código disciplinar da História no Brasil dividida em quatro períodos: construção do código disciplinar da História no Brasil (1838-1931); consolidação do código disciplinar da História (1931-1971); crise do código disciplinar da História (1971-1984); e reconstrução do código disciplinar da História (1984-dias atuais).

Freitas (2004, 2006), ao estudar os manuais de Jonathas Serrano e Murilo Mendes, identifica a importancia da Pedagogia, principalmente do pensamento de John Dewey, na composição da uma espécie de "pedagogía histórica". Dessa forma, o pesquisador identifica a importância dos métodos pedagógicos nesses manuais destinados aos professores.

Na dissertação de mestrado intitulada Os manuais de Didática da História e a constituição de uma epistemologia da Didática da História, Rodrigues Júnior (2010) investigou a relação entre a História - particularmente as contribuições da Teoria da História - e os saberes pedagógicos na constituição da Didática da História em três manuais contemporâneos. Como resultados da pesquisa, o autor indicou que os manuais analisados demonstram a "pedagogização do conhecimento histórico", conforme Schmidt (2004). Isso se deve à forte influência dos saberes pedagógicos, ou seja, da Pedagogia e da Psicologia e ao conceito de transposição didática de Chevallard (2005).

Por outro lado, Rodrigues Júnior apontou a existência de um diálogo original entre a Teoria da História e o método de ensino nos manuais analisados, constituindo-se, desta forma, uma Didática específica, a Didática da História. Isso se deve ao fato de que nesses manuais analisados, a metodologia de ensino tem como referência o próprio método histórico, ou seja, as autoras dos manuias relacionam a Teoria da História e os saberes pedagógicos na proposição de métodos de ensino da História.

As pesquisas com manuais destinados aos professores têm mostrado a possibilidade de entender estes textos a partir de algumas características que serão exploradas a seguior, a partir dos dados de pesquisa empírica desenvolvida por Rodrigues Junior (2015). 


\section{A Diversidade de Manuais Pedagógicos de Didática da}

\section{História: Um Inventário}

Partindo da periodização proposta por Schmidt (2012) foram inventariados manuais destinados aos professores de História produzidos no contexto de reconstrução do código disciplinar da História (1984-????), mais especificamente no período posterior à publicação dos Parâmetros Curriculares Nacionais - PCN de História (1997 e 1998). O recorte temporal foi realizado a partir da compreensão de que este texto oficial representou um momento de tentativa de renovação do ensino da História (AVELAR, 2011).

A busca realizada resultou na identificação de vinte (20) manuais destinados aos professores produzidos no período entre 1997 e 2013. Esses manuais constituíram o corpus documental analisado para a produção de tese de doutorado (RODRIGUES JÚNIOR, 2015), com a finalidade de compreender a natureza desses manuais e identificar suas características:

Quadro 1: Manuais de didática da história inventariados

\begin{tabular}{|c|c|c|c|}
\hline MANUAL & AUTOR & EDITORA & ANO \\
\hline $\begin{array}{c}\text { Didática e Prática de Ensino de } \\
\text { História }\end{array}$ & Selva Guimarães Fonseca & Papirus & 2005 \\
\hline $\begin{array}{c}\text { Ensino de História: } \\
\text { fundamentos e métodos }\end{array}$ & $\begin{array}{c}\text { Circe Maria Fernandes } \\
\text { Bittencourt }\end{array}$ & Cortez & 2004 \\
\hline Ensinar História & $\begin{array}{c}\text { Maria Auxiliadora Schmidt e } \\
\text { Marlene Cainelli }\end{array}$ & Scipione & 2004 \\
\hline $\begin{array}{c}\text { O ensino de História e seu } \\
\text { currículo }\end{array}$ & $\begin{array}{c}\text { Geraldo Balduíno Horn e Geyso } \\
\text { Dongley Germinari }\end{array}$ & Vozes & 2006 \\
\hline Ensinar História no século XXI & $\begin{array}{c}\text { Selva Guimarães Fonseca e } \\
\text { Marcos Silva }\end{array}$ & Papirus & 2007 \\
\hline $\begin{array}{c}\text { A atividade de ensino de } \\
\text { História: processo de formação } \\
\text { de professores e alunos }\end{array}$ & Olavo Pereira Soares & $\begin{array}{l}\text { Junqueira } \\
\text { \&Marin }\end{array}$ & 2008 \\
\hline $\begin{array}{c}\text { Aprendendo História: reflexão e } \\
\text { ensino }\end{array}$ & $\begin{array}{c}\text { Marieta de Moraes Ferreira e } \\
\text { Renato Franco }\end{array}$ & FGV & 2009 \\
\hline Fazer e ensinar História & Selva Guimarães Fonseca & Dimensão & 2009 \\
\hline $\begin{array}{c}\text { Ensinar e aprender História: } \\
\text { história em quadrinhos e } \\
\text { canções }\end{array}$ & $\begin{array}{c}\text { Adriane de Quadros Sobanski, } \\
\text { Edilson Aparecido Chaves, João } \\
\text { Luis da Silva Bertolini e } \\
\text { Marcelo Fronza }\end{array}$ & $\begin{array}{c}\text { Base } \\
\text { editorial }\end{array}$ & 2010 \\
\hline $\begin{array}{c}\text { Fundamentos teórico- } \\
\text { metodológicos para o ensino da } \\
\text { História (anos iniciais) }\end{array}$ & Itamar Freitas & $\begin{array}{c}\text { Editora da } \\
\text { Universid } \\
\text { ade }\end{array}$ & 2010 \\
\hline
\end{tabular}




\begin{tabular}{|c|c|c|c|}
\hline & & $\begin{array}{l}\text { Federal de } \\
\text { Sergipe }\end{array}$ & \\
\hline $\begin{array}{l}\text { Ensino de História e } \\
\text { experiências }\end{array}$ & $\begin{array}{l}\text { Ana Nemi, João Carlos Martins } \\
\text { e Diego Luiz Escanhuela }\end{array}$ & FTD & 2010 \\
\hline Ensino de História & $\begin{array}{c}\text { Katia Maria Abud, André } \\
\text { Chaves de Melo Silva e Ronaldo } \\
\text { Cardoso Alves }\end{array}$ & $\begin{array}{l}\text { Cencage } \\
\text { Learning }\end{array}$ & 2011 \\
\hline $\begin{array}{c}\text { Os desafios do ensino de } \\
\text { História: problemas, teorias e } \\
\text { métodos }\end{array}$ & Alexandre de Sá Avelar & IBPEX & 2011 \\
\hline $\begin{array}{l}\text { A docência em História: } \\
\text { reflexões e propostas de ações }\end{array}$ & $\begin{array}{l}\text { Carmem Zeli de Vargas Gil e } \\
\text { Dóris Bittencourt Almeida }\end{array}$ & Edelbra & 2012 \\
\hline $\begin{array}{c}\text { Metodologia do ensino de } \\
\text { História }\end{array}$ & José Antônio Vasconcellos & $\begin{array}{l}\text { Intersaber } \\
\text { es }\end{array}$ & 2012 \\
\hline $\begin{array}{l}\text { Vivenciando a História - } \\
\text { Metodologia do Ensino da } \\
\text { História }\end{array}$ & Marta de Souza Lima Brodbeck & $\begin{array}{c}\text { Base } \\
\text { Editorial }\end{array}$ & 2012 \\
\hline História & $\begin{array}{l}\text { Regina Soares de Oliveira, } \\
\text { Vanusia Lopes de Almeida e } \\
\text { Vitória Azevedo Fonseca }\end{array}$ & Blucher & 2012 \\
\hline $\begin{array}{l}\text { Ensino de História: diálogos } \\
\text { com a literatura e a fotografia }\end{array}$ & $\begin{array}{c}\text { Júlio Pimentel Pinto e Maria } \\
\text { Inez Turazzi }\end{array}$ & Moderna & 2012 \\
\hline $\begin{array}{c}\text { Educação patrimonial no } \\
\text { ensino de História nos anos } \\
\text { finais do Ensino Fundamental: } \\
\text { conceitos e práticas }\end{array}$ & $\begin{array}{c}\text { Cristina Reis Figueira e Lílian } \\
\text { Lisboa Miranda }\end{array}$ & $\begin{array}{l}\text { Edições } \\
\text { SM }\end{array}$ & 2012 \\
\hline $\begin{array}{l}\text { Capítulos de História: } o \\
\text { trabalho com fontes }\end{array}$ & Marcella Lopes Guimarães & $\begin{array}{l}\text { Aymará } \\
\text { Educação }\end{array}$ & 2012 \\
\hline
\end{tabular}

O inventário evidenciou que, assim como constatado por Hegeto e Garcia (2012) com relação aos manuais de Didátic0a Geral, houve um crescimento significativo de publicações destinadas à orientação dos professores para o ensino de História a partir de 2009, constatndo-se também a reedição de obras anteriores ao período. Do ponto de vista das editoras responsáveis pela publicação dos manuais observou-se uma diversificação, com a presença de grupos economicamente fortes mas também de editoras de menor porte.

Uma hipótese possível para essa expansão é a existência do Programa Nacional Biblioteca da Escola - PNBE do Professor, mantido pelo Governo Federal, que se destina à aquisição de obras de apoio ao trabalho docente. Entre os títulos inventariados, oito manuais fazem parte do PNBE do Professor, representando $40 \%$ da produção no período. Os documentos oficiais do programa indicam explicitamente que as obras que interessam ao 
programa devem contribuir para as atividades de planejamento do ensino e para aplicação de atividades na sala de aula ${ }^{4}$.

Essa constatação sugere retomar, aqui, as contribuições de Apple (1995) para colocar em questão as relações entre a produção crescente desses manuais didáticos e o mercado editorial, na perspectiva de uma economia política dos textos didáticos. Segundo Garcia (2013, p. 75):

\begin{abstract}
Além de ser um artefato cultural, os livros também envolvem, além dos autores, as editoras que os produzem e comercializam, e ainda os consumidores. Como se sabe, no caso brasileiro, na produção de livros, predominam hoje os grupos de capital internacional, grandes grupos, restando poucas editoras brasileiras. Pequenas editoras, que se destacaram na proposição de livros alternativos do ponto de vista didático na década anterior, foram praticamente todas fechadas ou compradas por outras de maior porte, entre as quais as pertencentes a grupos espanhóis, nos anos de 1990.
\end{abstract}

A possibilidade de participar de editais abertos pelo Governo Federal, portanto, parece ter influenciado a produção de manuais específicos para orientação dos professores em suas práticas; e, nesse movimento, parece ter estimulado a participação de editoras de menor poder econômico - em direção um pouco diferente do que ocorreu com os livros didáticos para alunos, como fora apontado por Garcia em seu trabalho citado. De qualquer forma, o resultado do inventário realizado possibilita essa interpretação sustentada nas contribuições de Apple (1995), para evidenciar o papel do Estado brasileiro como o maior consumidor de livros escolares, incluindo-se manuais destinados aos professores.

Reafirma-se essa interpretação com as contribuições de Batista ao examinar relações entre os livros didáticos e a profissão docente, especialmente do ponto de vista das condições de exercício da profissão. Para Batista (2000, p. 563):

[...] é no mercado escolar, que acolhe e utiliza o livro didáticos (mas também nas relações que o campo da produção editorial mantém com esse mercado e com o mercado livreiro mais amplo, como já se

4“O PNBE do Professor tem por objetivo adquirir obras de referência para ajudar os professores da educação básica regular e da educação de jovens e adultos na preparação dos planos de ensi no e na aplicação de atividades em sala de aula com os alunos. A primeira edição do PNBE do Professor ocorreuem 2010 e teve investimento de R\$ 59 milhões. Na edição de 2013 está previsto investimentos da ordem de R \$90 milhões, pois há incremento no número de títulos e inclusão da educação infantil no novo edital". Informações no site: http://www.fnde.gov.br/programas/biblioteca-daescola/biblioteca-da-escola-apresentacao. 
apontou) que podem ser encontrados muitos fatores condicionantes das características materiais, funcionais e estruturais da produção didática de uma determinada sociedade, num determinado momento de sua história. O professor - suas características sociol[ogicas, suas relações com o saber e a educação, as formas pelas quais ele é formado e recrutado - constitui, como se viu, um desses fatores.

Portanto, pode-se dizer que as condições objetivas nas quais está sustentada a educação brasileira neste momento, as concepções que dirigem as propostas de formação de professores e as relações do mercado editorial com o mercado escolar contribuem para se entender o crescimento de obras destinadas ao professor verificada nas pesquisas sobre manuais de Didática Geral e de Didática da História.

A partir dessa constatação, reitera-se a relevância de buscar compreender a natureza desses manuais e explicitar que contribuições pretendem dar aos professores em suas práticas. Com esse objetivo, a pesquisa voltou-se à análise das obras localizadas no inventário realizado. Em uma abordagem qualitativa, apoiada em elementos sugeridos por Lessard-Hébert, Goyette, Boutin, (1990) e utilizando alguns procedimentos baseados nas proposições da análise de conteúdo, foi então realizada a leitura "flutuante" do conjunto de manuais localizados para "estabelecer contato com os documentos a analisar e em conhecer o texto deixando-se invadir por impressões e orientações" (apud BARDIN, 2011, p. 126).

Nessa primeira etapa de análise, foram examinados elementos como a estrutura da obra, sua organização em capítulos e os temas apresentados ao leitor, bem como buscou-se identificar semelhanças e diferenças entre elas, especialmente quanto à forma como os autores construíram as orientações ao professor.

As análises resultaram na identificação de estruturas distintas que possibilitaram uma proposta de categorização dos manuais de Didática da História em quatro tipos, os quais apresentam diferentes formas de dialogar com os professores, embora todas elas produzidas com a finalidade de, em alguma medida, orientar suas práticas de ensino da História.

a) manuais que dialogam com o professor por meio de reflexões sobre o ensino: as obras caracterizam-se por discutir o ensino da História, suas dificuldades e possibilidades; apresentam considerações de ordem teórica sobre o ensino, porém sem propor explicitamente alternativas sobre como ensinar. Não existem espaços específicos nessas obras para propostas ou sugestões de atividades. Dentro desta categoria foram encontrados manuais, como apresenta o quadro a seguir: 
Quadro 2: Manuais que dialogam com o professor de forma indireta por meio de reflexões sobre o ensino

\begin{tabular}{|c|c|c|c|}
\hline MANUAL & AUTOR & EDITORA & ANO \\
\hline $\begin{array}{c}\text { O ensino de História e seu } \\
\text { currículo }\end{array}$ & $\begin{array}{c}\text { Geraldo Balduíno Horn e } \\
\text { Geyso Dongley } \\
\text { Germinari }\end{array}$ & Vozes & 2006 \\
\hline $\begin{array}{c}\text { Ensinar História no século } \\
\text { XXI }\end{array}$ & $\begin{array}{c}\text { Selva Guimarães Fonseca } \\
\text { e Marcos Silva }\end{array}$ & Papirus & 2007 \\
\hline $\begin{array}{c}\text { Aprendendo História: } \\
\text { reflexão e ensino }\end{array}$ & $\begin{array}{c}\text { Marieta de Moraes } \\
\text { Ferreira e Renato Franco }\end{array}$ & FGV & 2009 \\
$\begin{array}{c}\text { Fundamentos teórico- } \\
\text { metodológicos para o ensino } \\
\text { da História (anos iniciais) }\end{array}$ & Itamar Freitas & $\begin{array}{c}\text { Editora da } \\
\text { Universidade } \\
\text { Federal de } \\
\text { Sergipe }\end{array}$ & 2010 \\
\hline
\end{tabular}

Fonte: Rodrigues Junior (2015).

b) manuais que dialogam com o professor indiretamente por meio de relatos de experiência de ensino: são obras que se caracterizam por problematizar o ensino da História, porém sem se dirigir diretamente ao professor para apresentar orientações sobre como ensinar. Apesar da não existência de espaços específicos para propostas ou sugestões de atividades, os autores dialogam com o professor apresentando relatos de experiência de ensino - produzidas pelos pórpiros autores enquanto professores que atuaram na escola básica. Dentro desta categoria foram encontrados três manuais, dois deles de autoria de Selva Guimarães Fonseca (Quadro 3).

Quadro 3: Manuais que dialogam com o professor de forma indireta por meio de relatos de experiências de ensino

\begin{tabular}{|c|c|c|c|}
\hline MANUAL & AUTOR & EDITORA & ANO \\
\hline $\begin{array}{c}\text { Didática e Prática de Ensino } \\
\text { de História }\end{array}$ & Selva Guimarães Fonseca & Papirus & 2005 \\
\hline $\begin{array}{c}\text { A atividade de ensino de } \\
\text { História: processo de } \\
\text { formação de professores } e \\
\text { alunos }\end{array}$ & Olavo Pereira Soares & $\begin{array}{c}\text { Junqueira } \\
\text { \&Marin }\end{array}$ & 2008 \\
\hline Fazer e ensinar História & Selva Guimarães Fonseca & Dimensão & 2009 \\
\hline
\end{tabular}

Fonte: Rodrigues Junior (2015)

c) manuais que dialogam com o professor de forma direta sobre a organização do ensino com ênfase em linguagens específicas: são obras que se caracterizam por apresentar possibilidades para o ensino da História focalizando o trabalho com linguagens específicas como histórias em quadrinhos, canções, literatura, fotografia, patrimônio e documentos 
escritos. Nestes manuais, os autores dialogam diretamente sobre a organização do ensino apresentando propostas de atividades em espaços específicos. Os manuais estão voltados à discussão do uso de linguagens específicas no ensino de História, mas sem problematizar o ensino da disciplina de maneira geral e sem referir-se a um conjunto estruturado e articulado de elementos didáticos. Dentro desta categoria foram encontrados seis manuais, como mostra o quadro a seguir:

Quadro 4: Manuais que dialogam com o professor de forma direta sob re a organização do ensino com ênfase em linguagens específicas

\begin{tabular}{|c|c|c|c|}
\hline MANUAL & AUTOR & EDITORA & ANO \\
\hline $\begin{array}{l}\text { Ensinar e aprender } \\
\text { História: história em } \\
\text { quadrinhos e canções }\end{array}$ & $\begin{array}{c}\text { Adriane de Quadros } \\
\text { Sobanski, Edilson Aparecido } \\
\text { Chaves, João Luis da Silva } \\
\text { Bertolini e Marcelo Fronza }\end{array}$ & Base editorial & 2010 \\
\hline Ensino de História & $\begin{array}{c}\text { Katia Maria Abud, André } \\
\text { Chaves de Melo Silva e } \\
\text { Ronaldo Cardoso Alves }\end{array}$ & $\begin{array}{l}\text { Cencage } \\
\text { Learning }\end{array}$ & 2011 \\
\hline $\begin{array}{c}\text { Ensino de História: } \\
\text { diálogos com a literatura e } \\
\text { a fotografia }\end{array}$ & $\begin{array}{c}\text { Júlio Pimentel Pinto e Maria } \\
\text { Inez Turazzi }\end{array}$ & Moderna & 2012 \\
\hline $\begin{array}{c}\text { Educação patrimonial no } \\
\text { ensino de História nos } \\
\text { anos finais do Ensino } \\
\text { Fundamental: conceitos e } \\
\text { práticas }\end{array}$ & $\begin{array}{l}\text { Cristina Reis Figueira e } \\
\text { Lílian Lisboa Miranda }\end{array}$ & Edições SM & 2012 \\
\hline História & $\begin{array}{c}\text { Regina Soares de Oliveira, } \\
\text { Vanusia Lopes de Almeida e } \\
\text { Vitória Azevedo Fonseca }\end{array}$ & Blucher & 2012 \\
\hline $\begin{array}{l}\text { Capítulos de História: } o \\
\text { trabalho com fontes }\end{array}$ & Marcella Lopes Guimarães & $\begin{array}{l}\text { Aymará } \\
\text { Educação }\end{array}$ & 2012 \\
\hline
\end{tabular}

Fonte: pesquisa do autor (2015)

d) manuais que dialogam com o professor de forma direta e explícita sobre a organização do ensino por meio de uma estrutura didática: são obras que se caracterizam por dialogar diretamente sobre a organização do ensino a partir de uma estrutura didáticaespecífica. Diferenciam-se do grupo anterior pois se voltam à discussão da disciplina de maneira geral, estruturando de forma relativamente orgânica uma proposta didática em torno de elementos como história do ensino de História, currículo de História, ensino e aprendizagem da História, avaliação em História e propostas ou sugestões de atividades em História. Dentro desta categoria foram encontrados sete manuais, listados no quadro a seguir: 
Quadro 5: Manuais que dialogam como professor de forma direta e explícita sobrea organização do ensino por meio de um estrutura didática

\begin{tabular}{|c|c|c|c|}
\hline MANUAL & AUTOR & EDITORA & ANO \\
\hline $\begin{array}{c}\text { Ensino de História: fundamentos } \\
\text { e métodos }\end{array}$ & $\begin{array}{c}\text { Circe Maria Fernandes } \\
\text { Bittencourt }\end{array}$ & Cortez & 2004 \\
\hline Ensinar História & $\begin{array}{c}\text { Maria Auxiliadora Schmidt e } \\
\text { Marlene Cainelli }\end{array}$ & Scipione & 2004 \\
\hline Ensino de História e experiências & $\begin{array}{c}\text { Ana Nemi, João Carlos } \\
\text { Martins e Diego Luiz } \\
\text { Escanhuela }\end{array}$ & FTD & 2010 \\
\hline $\begin{array}{l}\text { Os desafios do ensino de História: } \\
\text { problemas, teorias e métodos }\end{array}$ & Alexandre de Sá Avelar & IBPEX & 2011 \\
\hline $\begin{array}{c}\text { A docência em História: reflexões } \\
\text { e propostas de ações }\end{array}$ & $\begin{array}{c}\text { Carmem Zeli de Vargas Gil e } \\
\text { Dóris Bittencourt Almeida }\end{array}$ & Edelbra & 2012 \\
\hline $\begin{array}{c}\text { Metodologia do ensino de } \\
\text { História }\end{array}$ & José Antônio Vasconcellos & Intersaberes & 2012 \\
\hline $\begin{array}{c}\text { Vivenciando a História - } \\
\text { Metodologia do Ensino da } \\
\text { História }\end{array}$ & $\begin{array}{c}\text { Marta de Souza Lima } \\
\text { Brodbeck }\end{array}$ & $\begin{array}{c}\text { Base } \\
\text { Editorial }\end{array}$ & 2012 \\
\hline
\end{tabular}

Fonte: Rodrigues Junior (2015)

Com apoio no conceito de manual de Didática Específica apontado por Bufrem, Schmidt e Garcia (2006), de manual de Didática Especial conforme apresentado por Batista (2000) e de Manuais Pedagógicos na perspectiva proposta por Silva (2003, 2005), foi possível realizar comparações entre os quatro grupos de manuais. Nessa primier aetapa de análise, foi possível definir que, na constituição de manuais didáticos, são fundamentais a proposição de métodos e atividades de ensino. Essa decisão implicou a exclusão dos manuais das duas primeiras categorias do corpus documental examinado na segunda etapa de análise.

Por outro lado, os manuais que discutem linguagens específicas, embora destinados aos professores e compostos por propostas de atividades, não discutem a metodologia do ensino de maneira ampla, ou seja, não sugerem discussões sobre a natureza do ensinar e aprender História, mas apenas apresentam formas de instrumentalização dos professores de História para o uso de determinadas fontes em sala de aula. Assim, também deixaram de ser incluídos na segunda etapa de análise.

Enfim, os manuais que melhor se enquadram no conceito dos autores de referência são aqueles que, ao mesmo tempo em que discutem a metodologia do ensino da História de maneira ampla e de forma reflexiva, apresentam uma estrutura didática definida e propõem atividades de ensino de forma articulada, apontando para determinadas formas de organização do ato de ensinar.

Assim, após o inventário realizado e com base nos indícios de que seria possível uma reconceitualização dessas obras como manuais didáticos, optou-se pela análise dos 
seguintes manuais: Ensino de História: fundamentos e métodos (2004) de Circe Bittencourt, Ensino de História (2004) de Marlene Cainelli e Maria Auxiliadora Schmidt, Ensino de História e experiências (2010) de Ana Nemi, João Carlos Martins e Diego Luiz Eescanhuela, Os desafios do ensino de História: problemas, teorías e métodos (2011) de Alexandre de Sá Avelar, A docência em História: reflexões e propostas de ações (2012) de Carmem Zeli de Vargas Gil e Dóris Bittencourt Almeida, Metodolodia do ensino de História (2012) de José Antônio Vasconcellos, e, Vivenciando a História (2012) de Marta de Souza Lima Brodbeck.

Alguns resultados estão apresentados a seguir.

\section{Os Manuais Didáticos: Orientando O Ensino Da História Por Meio De Propostas Estruturadas}

Os sete (7) manuais analisados apresentam como primeira característica comum a intenção de contribuir com a formação inicial e continuada de professores ou dialogar com os professores de História. Nesta direção, os organizadores das coleções ou mesmo os autores das obras apresentam nas apresentações ou introduções a intenção de "oferecer aos professores em processo de formação, e aos que já atuam como profissionais da educação, subsídios formativos [...]" (BITTENCOURT, 2004, p. 13).

Tal intenção pode ser visualizada na estrutura didática composta por elementos que podem ser entendidos, na perspectiva dessas obras, como constituidores da Didática da História. Dentre eles: história do ensino de História, currículo de História, ensino e aprendizagem de História, avaliação em História e propostas ou sugestões de atividades.

A grande maioria dos manuais de Didática da História inicia a estrutura com capítulos ou subcapítulos que tratam da história do ensino da História no Brasil. Partindo de uma periodização cujo marco fundamental é a criação do Colégio Dom Pedro II em 1837, os manuais se propõem a contextualizar os professores na prática de ensino de História permitindo o conhecimento das formas de ensinar e aprender nos diferentes contextos históricos. O único manual a não dedicar um capítulo específico ao tema é o manual $A$ docência em História: reflexões e propostas de ações. Mesmo assim, as autoras tocam no tema no decorrer do texto.

Após discutir a história do ensino da História, ou mesmo como parte dessa contextualização, os(as) autores(as) discutem o currículo de História tendo como focos fundamentais os Parâmetros Curriculares Nacionais de História para as séries iniciais do 
Ensino Fundamental publicados em 1997 e para as séries finais publicado em 1998. Em todos os manuais são muitas as citações sobre ou dos PCNs. Em alguns casos, como no manual Metodologia do ensino de História, Vasconcellos (2012) apresenta o texto dos PCNs como sugestão de atividade para os professores em formação.

O terceiro elemento, ensino e aprendizagem de História, inclui discussões envolvendo os objetivos ou finalidades do ensino e da aprendizagem em História, o planejamento das aulas de História e mesmo da seleção de conteúdos na disciplina. Nessas discussões, mais uma vez, os(as) autores(as) dialogam por várias vezes com o texto dos PCNs de História e procuram identificar objetivos do ensino de História e mesmo as perspectivas sobre a aprendizagem presentes nestes textos oficiais. Além disso, destacam-se as referências feitas à psicologia da Educação no que diz respeito à aprendizagem, principalmente na perspectiva dos autores Jean Piaget e Lev Vygotsky.

O tema da avaliação em História é outro elemento presente na estrutura didática proposta pelos manuais analisados. Tal elemento didático, na maioria das vezes, está presente nos últimos capítulos. Apresenta-se como hipótese para essa localização do tema ao final do manual a concepção de que a prática pedagógica é encerrada no processo avaliativo enquanto verificação do conhecimento aprendido. Assim, a apresentação feita pelos autores de certa forma reproduz um mesmo modelo de estrutura de apresentação dos elementos didáticos, que se inicia com o debate sobre a história do ensino da História e termina com a avaliação.

O último e fundamental elemento que contribui para compreensão da estrutura didática, permitindo evidenciar e diferenciar os manuais destinados aos professores de História de outros tipos de literatura pedagógica são as propostas ou sugestões de atividades apresentadas pelos manuais.

Todos os manuais selecionados apresentam propostas ou sugestões de atividades, seja ao final de cada capítulo ou em capítulos específicos. Cabe ressaltar uma diferença fundamental nestas atividades: em algumas das obras - como nos manuais Ensino de História: fundamentos e métodos, Ensinar história, Ensino de História e experiências, Desafios do ensino de História: problemas, teorias e métodos; e Metodologia do ensino de História - são propostas atividades de duas naturezas: direcionadas ao leitor idealizado como professor formador, formado ou em formação; e outras especialmente direcionadas aos alunos da Educação Básica.

Bittencourt (2004), Cainelli e Schmidt (2004) e Nemi, Escanhuela e Martins (2010) apresentam sugestões de atividades para os professores em formação nos capítulos em que tratam das questões teóricas como: história do ensino da História, currículo de História, ensino e aprendizagem de História e avaliação em História. Avelar (2011) e Vasconcellos (2012) propõem atividades de autoavaliação cujo objetivo é avaliar os leitores sobre os 
conteúdos discutidos em todos os capítulos, sendo as atividades de aprendizagem direcionadas para ações com alunos da Educação Básica.

Os manuais $A$ docência em História: reflexões e propostas de ações; e Vivenciando a História - Metodologia do Ensino da História apresentam sugestões de atividades exclusivamente direcionadas aos alunos da Educação Básica. Há atividades que os leitores podem realizar como parte de seu processo formativo em Didática da História; e há atividades que o leitor pode utilizar no seu trabalho com os alunos, de certa forma aproximando-se da ideia de aplicação das propostas contidas nos manuais.

\section{Algumas Considerações Finais}

Com base nos resultados produzidos pela análise empírica, pode-se concordar com Schmidt $(2008,2012)$ e Urban (2009) na direção de que os manuais permitem evidenciar a constituição do código disciplinar da História e da Didática da História.

Os manuais cumprem em menor ou maior grau as três tarefas da Didática da História elencadas por Bergmann (1990): empírica, reflexiva ou normativa. A tarefa empírica procura entender, nos processos de ensino e aprendizagem, a elaboração e a recepção do conhecimento histórico. A tarefa reflexiva busca entender, nos processos de ensino e aprendizagem, as intenções práticas da disciplina e as possibilidades de ensino. A tarefa normativa propõe entender a fundamentação da disciplina, de forma a demonstrar como e o que deve ser ensinado.

Os sete manuais analisados cumprem a tarefa empírica ao discutirem a história do ensino de história entendida como uma forma de compreender os processos de ensino e de recepção do conhecimento histórico no tempo e ao se configurarem enquanto resultado de práticas empíricas das(os) autoras(es) na Educação Básica e Superior. Também cumprem a tarefa reflexiva ao discutirem o currículo, o ensino e a aprendizagem em História enquanto as intenções propostas pelos textos oficiais e as possibilidades que estes abrem a prática docente em História, algumas vezes com apoio em resultados de pesquisas realizadas. Por fim, cumprem a tarefa normativa ao discutirem a avaliação em História e proporem um caminho para o ensino, inclusive com atividades ou sugestões de atividades, indicando o quê e como os conhecimentos históricos devem ser aprendidos.

Apesar de defender a ideia da presença das três tarefas nesse grupo de manuais analisados, constata-se que a tarefa normativa ocupa espaço privilegiado nas discussões, 
tendo em vista que "o que deveria ser apreendido" (BERGMANN, 1990, p. 29) parece ser a grande questão posta pelos manuais didáticos, conteúdo privilegiado pelos autores para o diálogo com os professores, na direção de orientá-los sobre como ensinar História em sua atividade nas aulas.

Tal constatação pode ser inferida a partir da análise da estrutura didática dos manuais. Dos cinco (5) elementos da Didática da História presentes nos manuais, quatro (4) tratam direta ou indiretamente da tarefa normativa (BERGMANN, 1990). Os capítulos que tratam do currículo de História dialogam com o texto dos PCNs na direção de indicar aos professores o que deve ser ensinado nas aulas de História.

Os capítulos que abordam o ensino e a aprendizagem em História, além de dialogarem com os objetivos e finalidades do ensino da História indicados no texto dos PCNs, apresentam debates sobre as concepções de aprendizagem advindas da Psicologia construtivista, portanto indiretamente apresentando elementos relacionados a como ensinar História.

São apresentados, ainda, capítulos que tratam da avaliação em História, indicando debates quanto a concepções e formas de proceder para avaliar os alunos quanto aos conhecimentos históricos aprendidos na disciplina de História. Finalmente, os capítulos que tratam das sugestões de atividades apresentam diversas opções para desenvolver trabalhos tanto para professores em formação - pressupondo que o manual pode de ser utilizado por formadores de professores - e para os alunos da Educação Básica - dialogando então com porfssores que já atuam nas ecsolas e procuram orientações para o desenvolvimento de suas aulas.

Assim, defende-se a existência de uma especificidade constatada na caracterização dos sete manuais analisados, produzidos como manuais de Didática da História e destinados aos professores formadores, formados e em formação. Ainda, aponta-se que tais obras podem ser diferenciadas em relação a outras destinadas aos professores, em consequência de sua natureza didática configurada em uma estrutura que cumpre as tarefas da Didática da História propostas por Bergmann (1990).

A análise dos manuais permite afirmar que os(as) autores(as) organizaram intencionalmente os manuais a partir de elementos didáticos que têm a potencialidade de contribuir com os professores na organização do ensino. Nesta direção, constroem uma estrutura organicamente articulada, embora essa estrutura tenha um certo grau de variação, dependendo das teorias que os autores utilizam para sustentar as suas propostas.

Por fim, observa-se a possibilidade de definição dos manuais de Didática da História enquanto textos destinados aos professores com objetivo de contribuir para a formação inicial e continuada por meio de uma estrutura didática que perpassa as três (3) tarefas da 
Didática da História propostas por Bergmann (1990) configurando uma disciplina específica, a Didática da História.

\section{Referências}

ABUD, Katia Maria; MELO E SILVA, André Chaves de; ALVES, Ronaldo Cardoso. Ensino de História. São Paulo: Cencage Learning, 2013.

APPLE, M. W. Trabalho docente e textos: economia política das relações de classe e de gênero em Educação. Porto Alegre: Artes Médicas, 1995.

AVELAR, Alexandre de Sá. Os desafios do ensino de História: problemas, teorias e métodos. Curitiba: IBPEX, 2011.

BATISTA, Antônio Augusto Gomes. Um objeto variável e instável: textos, i mpressos e livros didáticos. In: ABREU, M. (Org.). Leitura, história e história da leitura. Campinas: Mercado de Letras, 2000. p. 529-575.

BARDIN, Laurence. Análise de conteúdo. São Paulo: Edições 70, 2011.

BERGMANN, Klaus. A história na reflexão didática. Revista Brasileira de História, São Paulo, v.9, n.19, p. 29-42, Set.89/fev.90.

BITTENCOURT, Circe Maria Fernandez. Ensinar História: fundamentos e métodos. São Paulo: Cortez, 2004.

Livro didático e saber escolar. Belo Horizonte: Autentica, 2008.

BRASIL. Parâmetros Curriculares Nacionais - História. Brasília: Ministério da Educação e Cultura, 1998.

BRODBECK, Marta de Souza Lima. Vivenciando a História - Metodologia do Ensino da História. Curitiba: Base Editorial, 2012.

BUFREM, Leilah Santiago; GARCIA, Tânia Maria Braga; SCHMIDT, Maria Auxiliadora. Os manuais destinados a professores como fontes para a História das formas de ensinar. Revista HISTEDBR, Campinas, n.22, p. 120-130, jun. 2006. 
CAINELLI, Marlene Rosa; SCHMIDT, Maria Auxiliadora. Ensinar História. São Paulo: Scipione, 2004.

CARVAlHO, Marta Maria Chagas de; TOLEDO, Maria Rita de Almeida. Biblioteca para professores e modelização das práticas de leitura: análise material das coleções Atualidades Pedagógicas e Biblioteca de Educação. In: SIMPÓSIO NACIONAL DE HISTÓRIA, 24., 2007, São Leopoldo. Anais... São Leopoldo: UNISINOS, 2007. p. 1-9.

CARVALHO, Marta Maria Chagas de. Modernidade pedagógica e modelos de formação docente. São Paulo em Perspectiva, v. 14, n. 1, p.111-120, 2000.

_. - _ _. A caixa de utensílios e o tratado: modelos pedagógicos, manuais de Pedagogia e práticas de leitura de professores. In: CONGRESSO BRASILEIRO DE HISTÓRIA DA EDUCAÇÃO, 4., 2006, Goiânia. A educação e seus sujeitos na história. Goiânia: Editora da UCG/Ed. vieira, 2006. v. 1. p. 81-82.

CHEVALLARD, Yves. La transposición didáctica: del saber sábio al saber enseñado. Buenos Aires: Aique, 2005.

CHOPPIN, Alain. História dos livros e das edições didáticas: sobre o estado da arte. Educação e Pesquisa, São Paulo, v.30, n.3, p. 549-566, set./dez. 2004.

FERNÁNDEZ, Raimundo Cuesta. La sociogenesis de uma disciplina escolar: La Historia. Barcelona: Pomares-corredor, 1997.

FERREIRA, Marieta de Moraes; FRANCO, Renato. Aprendendo História: reflexão e ensino. Rio de Janeiro: FGV, 2013.

FIGUEIRA, Cristina Reis; MIRANDA, Lilian Lisboa. Educação patrimonial no ensino de História nos anos finais do Ensino Fundamental: conceitos e práticas. São Paulo: Edições SM, 2012.

FONSECA, Selva Guimarães. Caminhos da história ensinada. Campinas: Papirus, 1993.

_. _ _ _. Didática e prática de Ensino de História. 4. ed. Campinas: Papirus, 2005. Fazer e ensinar História. Belo Horizonte: Dimensão, 2009.

FONSECA, Selva Guimarães; SILVA, Marcos. Ensinar História no século XXI. Campinas: Papirus, 2007.

FREITAS, Itamar. A pedagogia da história de Jonathas Serrano para o ensino secundário brasileiro (1913/1945). 2006. Tese (Doutorado em História da Educação) -Pontifícia Universidade Católica de São Paulo. São Paulo, 2006. 
A pedagogia da história de Murilo Mendes (São Paulo, 1935). Sæculum - Revista de História, João Pessoa, n.11, p. 162-175, ago./ dez., 2004.

FREITAS, Itamar. Fundamentos teórico-metodológicos para o ensino da História (anos iniciais). Sergipe: Editora da Universidade Federal de Sergipe, 2010.

GARCIA, Tânia M. F. Braga. Os Livros Didáticos na sala de aula. In: GARCIA, T. M. F. Braga; SCHMIDT, M. A.; VALLS, R. (Org.). Didática, História e manuais escolares: contextos iberoamericanos. Ijuí: Ed. Unijuí, 2013. p. 69-102.

GARCIA, Tânia M. F. Braga. Esquemas de trabalho para o domínio dos conhecimentos: módulos instrucionais de Didática Geral para formar professores na década de 1980. In: CONGRESO IBEROAMERICANO DE HISTORIA DE LA EDUCACIÓN LATINOAMERICANA: contactos, cruces y luchas en la historia de la educación latino-americana, 8., 2007, Buenos Aires. Anais... Buenos Aires, 2007. p.1-23.

GARCIA, Tânia Maria Figueiredo Braga. Do "como ensinar" ao "como educar": elementos do Código Disciplinar da Didática Geral no manual de João Toledo (1930). In: CONGRESSO LUSO-BRASILEIRO DE HISTÓRIA DA EDUCAÇÃO, 8., 2010, São Luís, MA. Infância, Juventude e relações de gênero da história da educação. São Luís, MA: EDUFMA, 2010. v. 1. p. 1-16.

GIL, Carmem Zeli de Vargas; ALMEIDA, Dóris Bittencourt. A docência em História: reflexões e propostas de ações. Porto Alegre: Edelbra, 2012.

GUEREÑA, Jean-Louis; OSSENBACH, Gabriela; POZO, María del Mar del. Manuales escolares en España, Portugal y América Latina (siglos XIX y XX). Madrid: Universidad Nacional de Educación a Distancia, 2005.

GUIMARÃES, Marcella Lopes. Capítulos de História: o trabalho com fontes. São Paulo: Aymará Educação, 2012.

HEGETO, Léia de C; GARCIA, Tânia M. F. Braga. Relações entre currículos de formação de professores e a disciplina de Didática Geral: perspectivas de análise a partir de manuais didáticos In: COLÓQUIO SOBRE QUESTÕES CURRICULARES, 10., COLÓQUIO LUSO BRASILEIRO DE CURRÍCULO, 6., 2012, Belo Horizonte, MG.

HORN, Geraldo Balduíno; GERMINARI, Geyso Dongley. O ensino de História e seu currículo: teoria e método. Petrópolis: Vozes, 2013.

NAGLE, Jorge. Educação e Sociedade na Primeira República. São Paulo: Edusp, 2009.

NEMI, Ana Lúcia Lana; ESCANHUELA, Diego Luiz; MARTINS, João Carlos. Ensino de História e experiências: o tempo vivido. São Paulo: FTD, 2010. 
OLIVEIRA, Regina Soares de; ALMEIDA, Vanusia Lopes de Almeida; FONSECA, Vitória Azevedo. História. São Paulo: Blucher, 2012.

PINTO, Júlio Pimentel; TURAZZI, Maria Inez. Ensino de História: diálogos com a literatura e a fotografia. São Paulo: Moderna, 2012.

RODRIGUES JUNIOR, Osvaldo. Os manuais de Didática da História e a constituição de uma epistemología da Didática da História. Dissertação (Mestrado em Educação) - Universidade Federal do Paraná, 2010.

.Os manuais de Didática da História no Brasil (1997-2014): entre tensões e intenções. 2015. Tese (Doutorado em Educação) - Universidade Federal do Paraná, 2015.

SCHMIDT, Maria Auxiliadora. História com pedagogia: a contribuição da obra de Jonathas Serrano na construção do código disciplinar da História no Brasil. Revista Brasileira de História, São Paulo, v. 24, n. 48, p. 189-219, 2004.

O aprender da História no Brasil: trajetórias e perspectivas. In: OLIVEIRA, Margarida Maria Dias de; CAINELLI, Marlene Rosa; OLIVEIRA, Almir Félix Batista de. Ensino de História: múltiplos ensinos em múltiplos espaços. Natal: EDFURN, 2008. p. 10-19.

SCHMIDT, Maria Auxiliadora. Os Parâmetros Curriculares e a formação do professor: algumas reflexões. In: ENCONTRO PERSPECTIVAS DO ENSINO DE HISTÓRIA, 3., 1999. p. 362-370. Disponivel em: <http://ojs.fe.unicamp.br/ged/FEH/article/view/5861>. Acesso em: 7 ago. 2015.

_ - _ _. O método é a maravilha da escola e a delícia do professor. Os manuais didáticos e a construção da prática de ensino de História. In: GUEREÑA, Jean-Louis; OSSENBACH, Gabriela; POZO, María del Mar del. Manuales escolares en España, Portugal y América Latina (siglos XIX y XX). Madrid: Universidad Nacional de Educación a Distancia, 2005.

História do ensino de História no Brasil: uma proposta de periodização. Revista História da Educação - RHE, Porto Alegre, v. 16, n. 37, p. 73-91, Maio/ago. 2012.

SILVA, Vivian Batista da. Uma história das leituras para professores análise da produção e circulação de saberes especializados nos manuais pedagógicos (1930-1971). Revista brasileira de história da educação, n. 6, p. 29-57, jul./dez. 2003.

Saberes em viagem nos manuais pedagógicos: construções da escola em Portugal e no Brasil (1870-1970). 2005. Tese (Doutorado em Educação) - Programa de Pós-Graduação em Educação da Universidade de São Paulo, 2005. 
SOARES, Olavo Pereira. A atividade de ensino de História: processo de formação de professores e alunos. São Paulo: Junqueira \& Marin, 2008.

SOBANSKI, Adriane de Quadros; BERTOLINI, João Luis da Silva; FRONZA, Marcelo; CHAVES, Edílson Aparecido. Ensinar e aprender História: histórias em quadrinhos e canções. Curitiba: Base Editorial, 2010.

URBAN, Ana Cláudia. Didática da História: percursos de um Código Disciplinar no Brasil e na Espanha. 2009. Tese (Doutorado em Educação) - Universidade Federal do Paraná, Curitiba, 2009.

VASCONCELLOS, José Antônio. Metodologia do ensino de história. Curitiba: Intersaberes, 2012.

VIDAL, Diana Gonçalves. O exercício disciplinado do olhar: livros, leituras e práticas de formação docente no Instituto de Educação do Distrito Federal (1932-1937). Bragança Paulista: EDUSF, 2001.

Recebido em 20.08.2016

Aprovado em 25.11.2016 